\title{
A systematic review and meta-analysis of lifestyle nursing interventions for patients with cardiovascular disease
}

\author{
Nan Zhang', Tian'e Fa ${ }^{2} \wedge$ \\ ${ }^{1}$ Department of Nursing, Tianjin Chest Hospital, Tianjin, China; ${ }^{2}$ Tianjin Chest Hospital, Tianjin, China \\ Contributions: (I) Conception and design: N Zhang; (II) Administrative support: T Fa; (III) Provision of study materials or patients: N Zhang; (IV) \\ Collection and assembly of data: T Fa; (V) Data analysis and interpretation: N Zhang; (VI) Manuscript writing: Both authors; (VII) Final approval of \\ manuscript: Both authors. \\ Correspondence to: Tian'e Fa. 261 Taierzhuang South Road, Jinnan District, Tianjin, China. Email: zn18920286885@163.com.
}

\begin{abstract}
Background: The purpose of this study was to compare the clinical efficacy and safety of post-treatment nursing intervention (NI) with routine nursing care (RC) of patients with cardiovascular disease (CVD).

Methods: PubMed, EMBASE, the Cochrane Library, the China National Knowledge database, and other databases were used to comprehensively evaluate post-treatment NI versus RC for patients with CVD. Review Manager 5.0 was used to assess the impact of the results in the selected articles. Forest map analysis, sensitivity analysis, and bias analysis were performed on the collected data.

Results: In total, eight studies met the inclusion criteria. The systolic blood pressure in the RC group was higher than that in the NI group ( $\mathrm{MD}=-3.72,95 \% \mathrm{CI}:-4.64$ to $\left.-2.80, \mathrm{P}<0.00001, \mathrm{I}^{2}=92 \%\right)$. The diastolic blood pressure in the NI group was lower than that in the RC group ( $\mathrm{MD}=-5.36,95 \% \mathrm{CI}:-6.55$ to -4.16 , $\mathrm{P}<0.00001, \mathrm{I}^{2}=96 \%$ ). There was a significant difference in fasting blood glucose levels between the NI group and the RC group ( $\mathrm{MD}=-5.00,95 \% \mathrm{CI}:-9.47$ to $-0.52, \mathrm{P}=0.03, \mathrm{I}^{2}=88 \%$ ). The total cholesterol in the NI group was lower than that in the RC group ( $\mathrm{MD}=-9.99,95 \% \mathrm{CI}:-14.52$ to $-5.45, \mathrm{P}<0.0001, \mathrm{I}^{2}=85 \%$ ). The triglyceride value of the NI group was lower than that of the RC group, with significant heterogeneity $\left(\mathrm{MD}=-24.24,95 \% \mathrm{CI}:-26.25\right.$ to $\left.-22.23, \mathrm{P}<0.0001, \mathrm{I}^{2}=96 \%\right)$. A sensitivity analysis and funnel plot indicated that the study was reliable and publication bias was limited.
\end{abstract}

Discussion: The results showed that the efficacy and safety of NI were superior to RC after treatment of CVD. NI is worth popularizing.

Keywords! Cardiovascular disease (CVD); nursing intervention; routine care

Submitted Jul 19, 2021. Accepted for publication Sep 18, 2021.

doi: 10.21037/apm-21-2189

View this article at: https://dx.doi.org/10.21037/apm-21-2189

\section{Introduction}

Cardiovascular disease (CVD) and its complications have a high incidence and mortality rate and present a global public health challenge (1-3). In recent decades, the control of CVD has tended to be stable, highlighting the problems of patient compliance with medication and changes in lifestyle. The effectiveness of medication adherence and nursing intervention (NI) have been reviewed previously, but few studies have examined adherence to lifestyle changes. This meta-analysis review aimed to determine the impact of NI on blood pressure control and adherence to lifestyle changes.

Currently, NI is widely used in the later stages of CVD treatment in many countries (4-6). It differs from the traditional idea of routine nursing care (RC) (7-9). NI is an individualized lifestyle education program based on remote

\footnotetext{
$\wedge$ ORCID: 0000-0002-5811-4065.
} 
nursing consultation by telephone and has been found to improve blood pressure control and other indicators and improve adherence to lifestyle recommendations. Therefore, to enhance the prevention and control of CVD risk factors, effective nursing measures should be employed in the later stages of CVD treatment. However, in China, our understanding of the post-discharge treatment of patients with CVD is limited.

The NI management plan is a comprehensive strategy. It usually involves a detailed telephone assessment and intervention designed to improve CVD patients' knowledge and support their lifestyle changes. A typical teleconsultation intervention provides health maintenance services for patients by telephone follow-up. A computerbased patient intervention is also considered a potentially effective strategy for improving the prognosis of patients. It focuses on the development of a network-based information transmission strategy, online patient support, and intervention. The internet-based intervention strategy enables patients to obtain available information on a daily basis without the need for face-to-face contact with health professionals. In addition, as an intervention tool, computers offer other advantages. They provide a private learning environment and immediate reinforcement of previously learned strategies. Because of the computerbased intervention strategy, more interactive information and intervention can be delivered to patients at a lower cost. Novel computer-based intervention strategies focus on self-management, reduce the risk factors of CVD, and are more conducive to reducing secondary CVD. To date, there has been no evaluation of the effectiveness of NI reminder programs. Therefore, we conducted a meta-analysis to compare the differences between post-treatment NI and RC. Our objective was to evaluate whether NI can improve the existing primary prevention strategies for cardiovascular risk factor management. We present the following article in accordance with the PRISMA reporting checklist (available at https://dx.doi.org/10.21037/apm-21-2189).

\section{Methods}

\section{Search strategy}

We conducted a literature search of PubMed, the Cochrane Library, EMBASE, and the China National knowledge database for the following keywords: (I) cardiovascular disease; (II) nursing intervention; (III) routine nursing. We searched for articles dated January 1999 to October 2016 that focused on NI and routine nursing care following CVD treatment. To improve the sensitivity of the search strategy, we manually cross-searched the reference list of retrieved documents. We used the Boolean operator "and" to obtain a list of two or more words used in the search article. The literature search was not limited to any specific published language so as to discover the maximum number of relevant publications.

\section{Selection process}

After determining the research parameters, we reviewed the available literature and included articles in line with the following research parameter standards: randomized controlled trials that involved:

(I) A comparative study of NI versus RC;

(II) Patients receiving treatment for CVD;

(III) Efficacy of treatment for patients with CVD;

(IV) Articles where the full text was provided.

Excluded studies were determined by the following criteria:

(I) Nonrandomized studies;

(II) Other patients without CVD;

(III) Studies lacking available data or comparable results.

\section{Data extraction}

Two researchers independently reviewed the complete text, and the quality of the study was assessed. The relevant research data were extracted, including essential information such as the year of publication and the name of the first author, sample size, age, and the physical condition of each group. We also extracted detailed information about the interventions and results of each study.

\section{Statistical analysis}

Review Manager (Version 5.0, The Cochrane Collaboration, 2011) was used to estimate the outcomes among the selected reports. For continuous variables, the mean difference was calculated. The $\mathrm{I}^{2}$ statistic, a quantitative measure of inconsistency, was used to measure heterogeneity across studies. Studies with an $\mathrm{I}^{2}$ of $25-50 \%$ were considered to have low heterogeneity, an $\mathrm{I}^{2}$ of $50-75 \%$ was deemed to reflect moderate heterogeneity, and an $\mathrm{I}^{2}>75 \%$ reflected high heterogeneity. If the $\mathrm{I}^{2}$ was $>50 \%$, potential sources of heterogeneity were tested by conducting a sensitivity analysis by eliding each study in turn to investigate the 


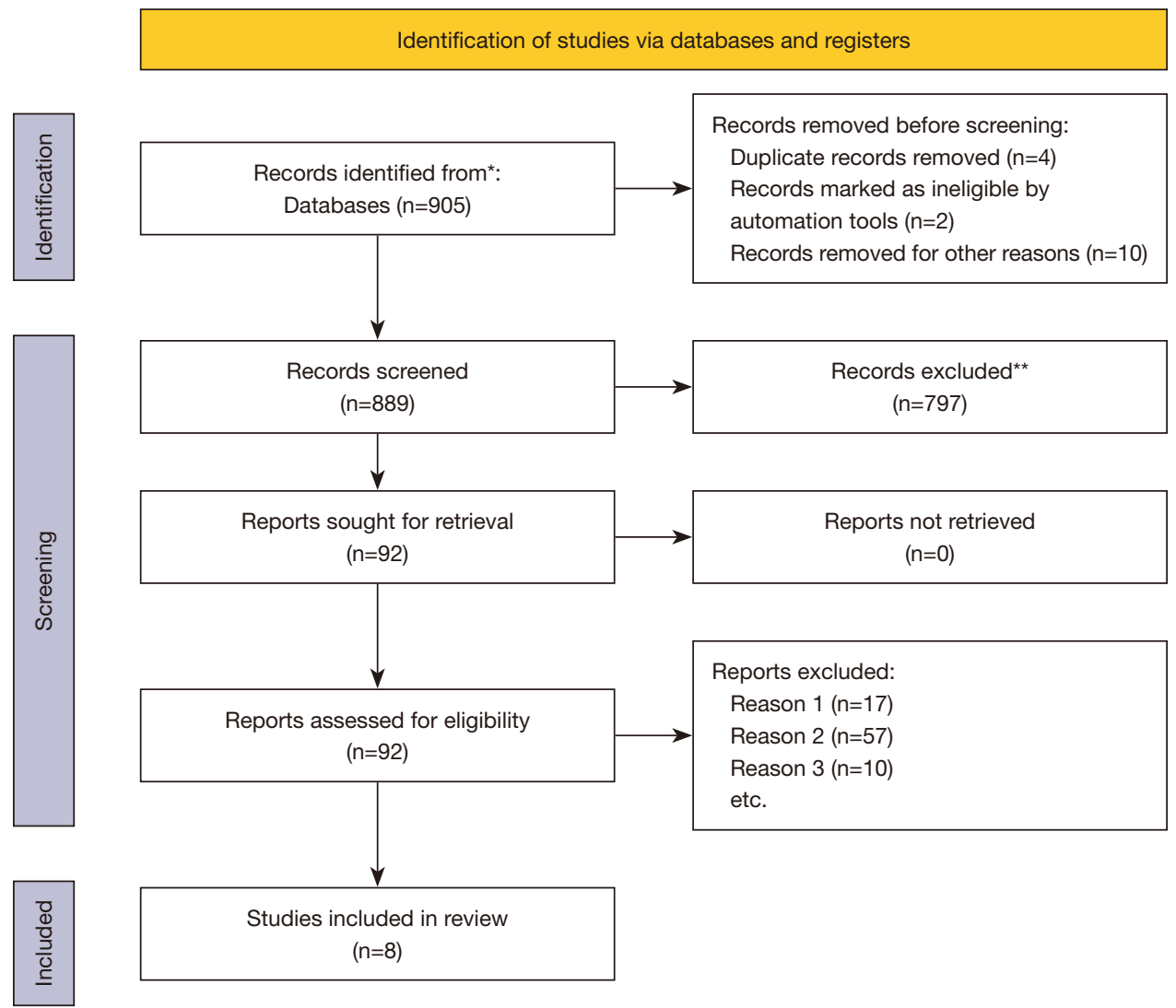

Figure 1 Flow diagram of the study selection. *, consider, if feasible to do so, reporting the number of records identified from each database or register searched (rather than the total number across all databases/registers); **, if automation tools were used, indicate how many records were excluded by a human and how many were excluded by automation tools. From: Page MJ, McKenzie JE, Bossuyt PM, Boutron I, Hoffmann TC, Mulrow CD, et al. The PRISMA 2020 statement: an updated guideline for reporting systematic reviews. BM7 2021;372:n71. doi: 10.1136/bmj.n71.

influence of a single study on the combined estimates. Furthermore, when heterogeneity was observed, a randomeffects model was adopted; otherwise, a fixed-effects model was used. Funnel plots were used to investigate potential publication bias.

\section{Results}

\section{Study selection}

Our initial database search is shown in Figure 1. The flow chart reflects the search process and reasons for exclusion. According to our search criteria, a total of 889 articles were initially identified, 797 duplicate articles were excluded, and 92 papers were available for analysis. A further 57 articles were excluded from the study due to poor research design, insufficient data, or article type. Eight papers were included in the final analysis (10-17).

\section{Characteristics of included studies}

The eight articles in Table 1 were published between 1999 and 2016. Sample sizes ranged from 4 to 762 . The extracted data included the type of study and the total number of patients included in each group. The content consisted of author, year of publication, country/region, age, grouping, and sample size. The analysis included 3,162 patients. The characteristics of the research are shown in Table 1.

\section{Risk of bias}

After conducting a risk assessment, we found only one study that displayed a reporting bias. One other study showed 
Table 1 Characteristics of the meta-analysis of NI versus RC

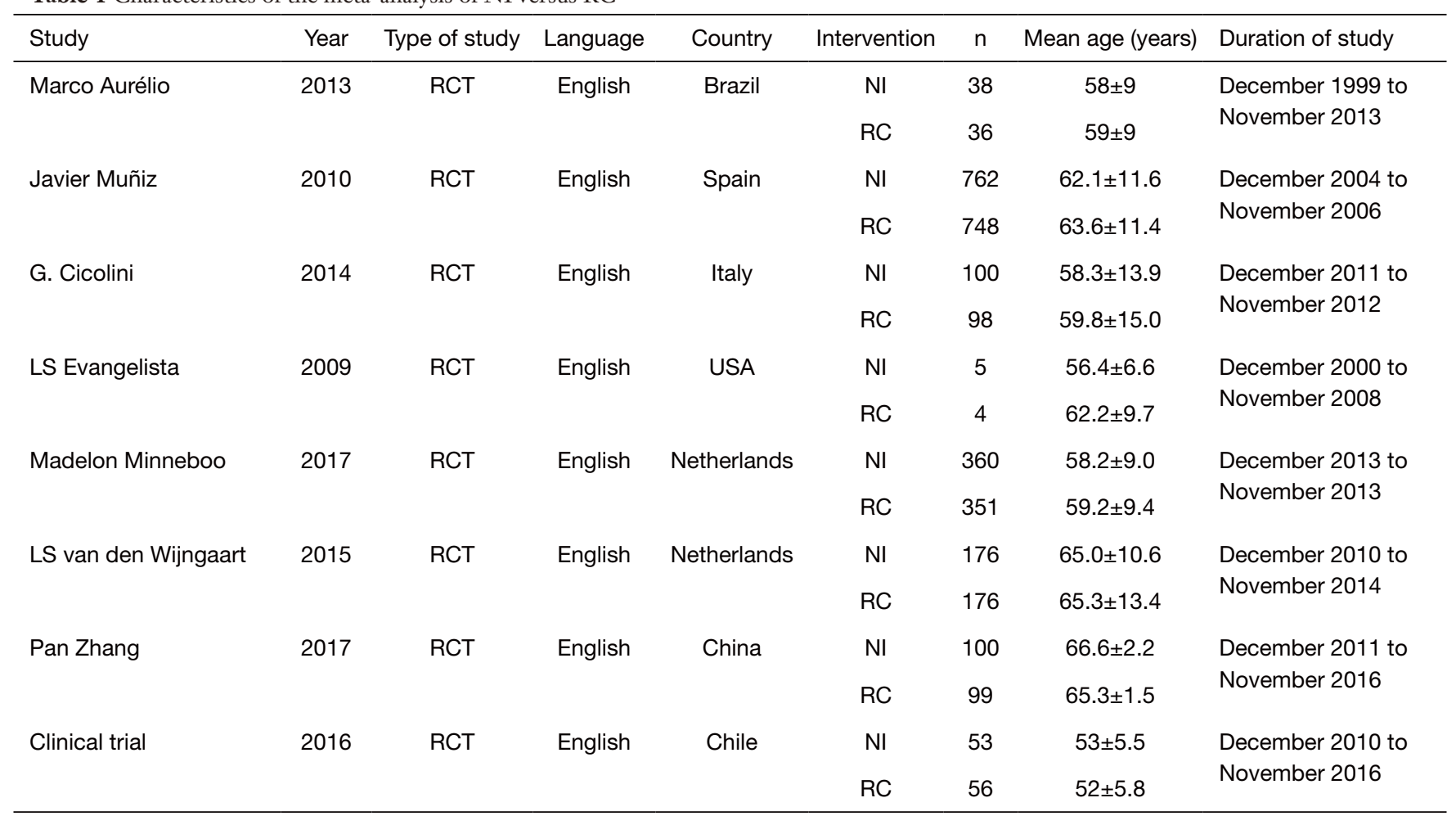

$\mathrm{NI}$, nursing intervention; $\mathrm{RC}$, nursing care; $\mathrm{RCT}$, randomized controlled trial.

a tendency towards a reporting bias. The Cochrane bias risk assessment tool was used in six clinical trials to assess the chance of patient selection bias. After evaluation, we concluded that six studies had no risk of bias. The remaining two studies showed some risk of bias. The detailed results of the quality assessment are shown in Figures 2 and 3.

\section{Meta-analysis results}

In the NI group, blood pressure, blood glucose, total cholesterol, and triglyceride levels of patients with CVD were better than those in the RC group.

The means and standard deviations of systolic blood pressure were reported in six articles (Figure 4). Heterogeneity test results showed that the systolic blood pressure of the RC group was higher than that of the NI group ( $M D=-3.72$, 95\% CI: -4.64 to $-2.80, \mathrm{P}<0.00001, \mathrm{I}^{2}=92 \%$ )

This meta-analysis included five studies that reported the differences between the NI and RC groups by comparing the means and standard deviations. Figure 5 shows the heterogeneity between the NI and RC groups. The results showed that the diastolic blood pressure in the NI group was lower than that in the RC group ( $\mathrm{MD}=-5.36,95 \% \mathrm{CI}$ : -6.55 to $\left.-4.16, \mathrm{P}<0.00001, \mathrm{I}^{2}=96 \%\right)$.

As shown in Figure 6, the heterogeneity of fasting blood glucose was evaluated based on a fixed-effects model. No significant heterogeneity was observed in these studies. The results showed that there was a significant difference in fasting blood glucose levels between the $\mathrm{NI}$ and $\mathrm{RC}$ groups $\left(\mathrm{MD}=-5.00,95 \% \mathrm{CI}:-9.47\right.$ to $\left.-0.52, \mathrm{P}=0.03, \mathrm{I}^{2}=88 \%\right)$.

Figure 7 compares the total cholesterol values between the NI and RC groups. Five studies described the subtle differences in heterogeneity between the NI and the RC groups. The results showed that the total cholesterol of the NI group was lower than that of the RC group ( $M D=-9.99$, $95 \%$ CI: -14.52 to $\left.-5.45, \mathrm{P}<0.0001, \mathrm{I}^{2}=85 \%\right)$

The heterogeneity evaluation indicated that five studies showed significant heterogeneity in the triglyceride values between the NI and RC groups (MD $=-24.24,95 \% \mathrm{CI}$ : -26.25 to $-22.23, \mathrm{P}<0.0001, \mathrm{I}^{2}=96 \%$ ) (Figure 8).

A sensitivity analysis was performed to examine which parameters significantly influenced the system or model to determine its stability. Except for the relative outliers, the results showed that, for heterogeneity, the sensitivity 


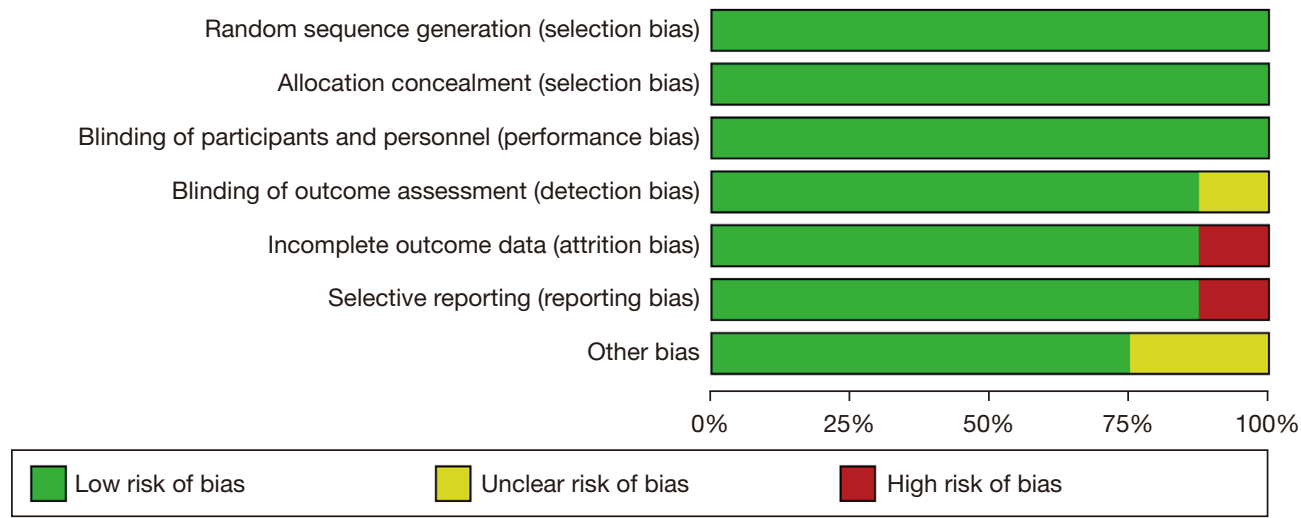

Figure 2 Quality assessment of included studies.

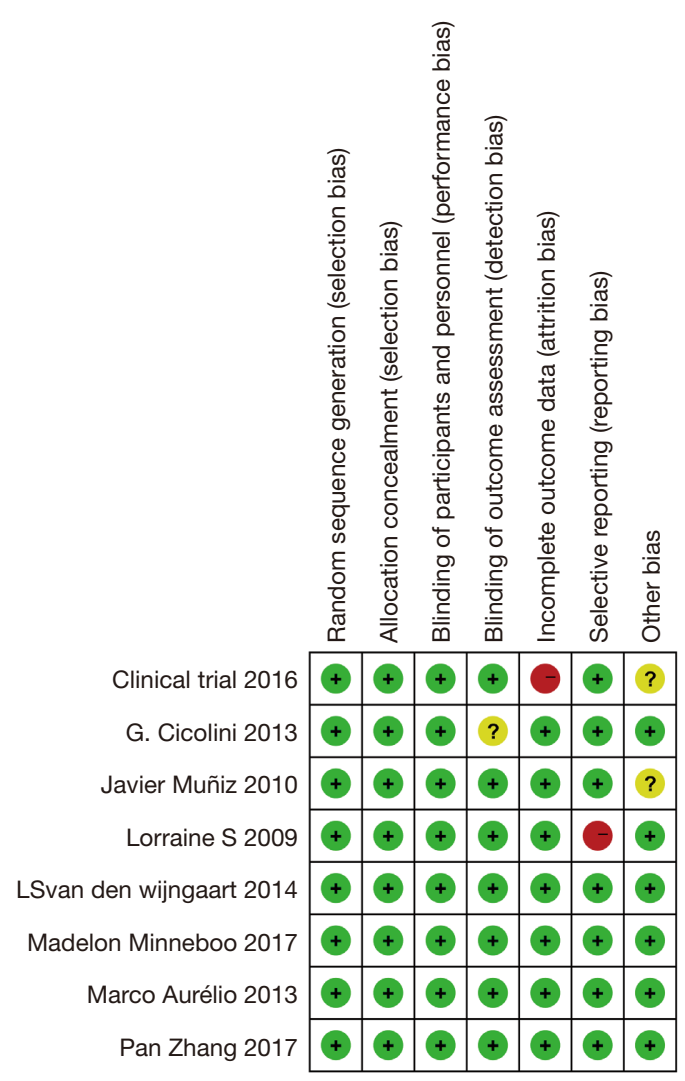

Figure 3 Assessment of the quality of the included studies: low risk of bias (green hexagons); unclear risk of bias (blank hexagons); and high risk of bias (red hexagons).

of systolic pressure did not change, but its $\mathrm{P}$ value changed from 0.01 to 0.23 . The results showed that the heterogeneity was mainly attributed to the Julio study in 2016, as shown in Figure 9.

\section{Publication bias analysis}

A funnel plot was used to analyze publication bias and included a total of six studies. The results showed no deviation due to the excellent symmetry of the funnel plot (Figure 10).

\section{Discussion}

Eight studies met the inclusion criteria to evaluate the efficacy and safety of NI compared with RC $(18,19)$. The meta-analysis of these studies showed a significant difference in systolic and diastolic blood pressure between the groups (20). The NI group's systolic blood pressure and fasting blood glucose were lower than that of the RC group. The total cholesterol and triglyceride levels were lower in the NI group than in the RC group.

NI programs included routine CVD prevention and guidance education for all patients (21-23). Patients in the NI group also received email reminders and calls from nursing care managers at weekly or monthly intervals up to six months post-discharge $(24,25)$. The emails contained a reminder plan of the need to adhere to a healthy lifestyle and follow current guidelines. The nursing initiatives were designed to improve perioperative treatment measures and promote patients' rapid recovery.

van Ballegooijen et al. (26) reported a comparison of the differences between the NI and RC groups. NI was added to the treatment of CVD patients and compared with traditional nursing (27-29). The results showed that NI promoted postoperative recovery, reduced blood pressure, blood sugar, total cholesterol, and triglyceride levels. NI was also shown to reduce postoperative hospitalization and 


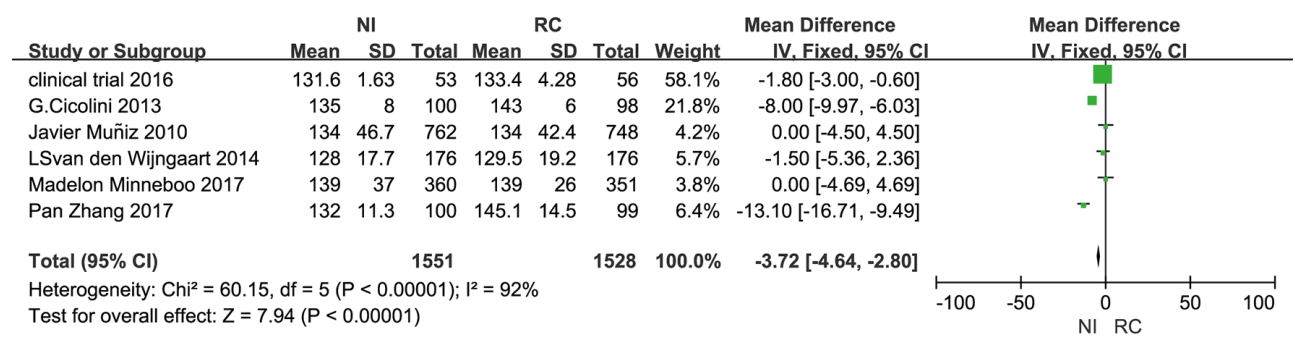

Figure 4 Forest plot of systolic blood pressure comparisons between the NI and RC groups. NI, nursing intervention; RC, nursing care.

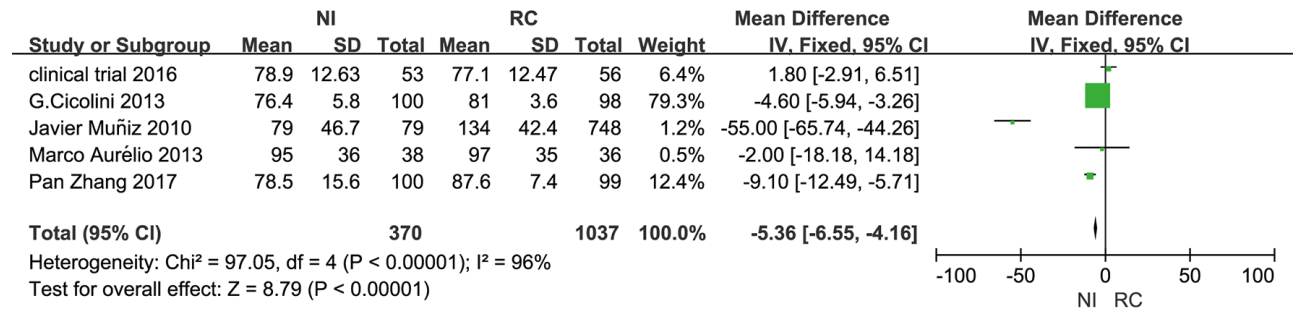

Figure 5 Forest plot of diastolic blood pressure comparisons between the NI and RC groups. NI, nursing intervention; RC, nursing care.

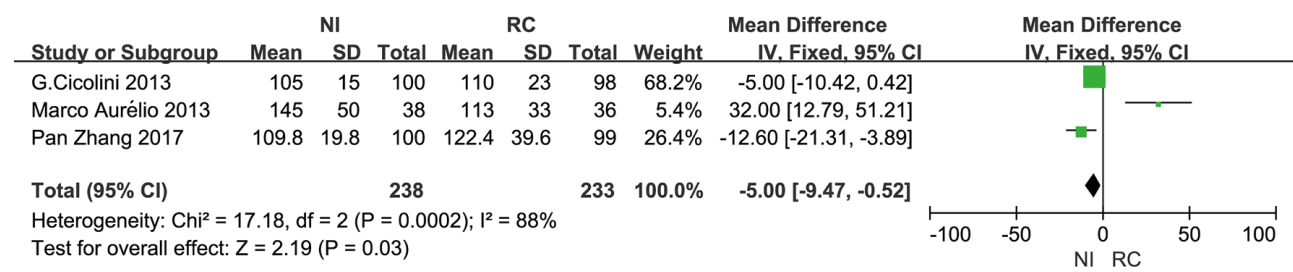

Figure 6 Forest plot of fasting blood glucose comparisons between the NI and RC groups. NI, nursing intervention; RC, nursing care.

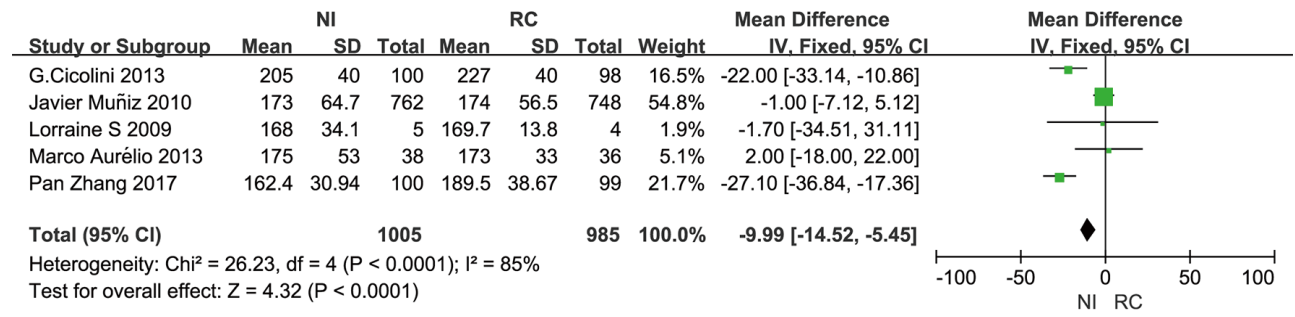

Figure 7 Comparison of total cholesterol between the NI and RC groups. NI, nursing intervention; RC, nursing care.

minimize the stress response of patients.

Similar to our results, Hendriks et al. (30) reported differences in various indicators between NI and RC groups (31-33). Results indicated that NI promoted postoperative rehabilitation, reduced blood pressure, blood glucose, total cholesterol, and triglycerides. It would appear from the above results that NI can be safely used in the treatment of most CVDs.

However, the number of CVD treatment protocols using NI remains small, and the NIs applied in current clinical practice are not widely promoted. Furthermore, the clinical research of CVD treatment lacks comprehensive data, and 


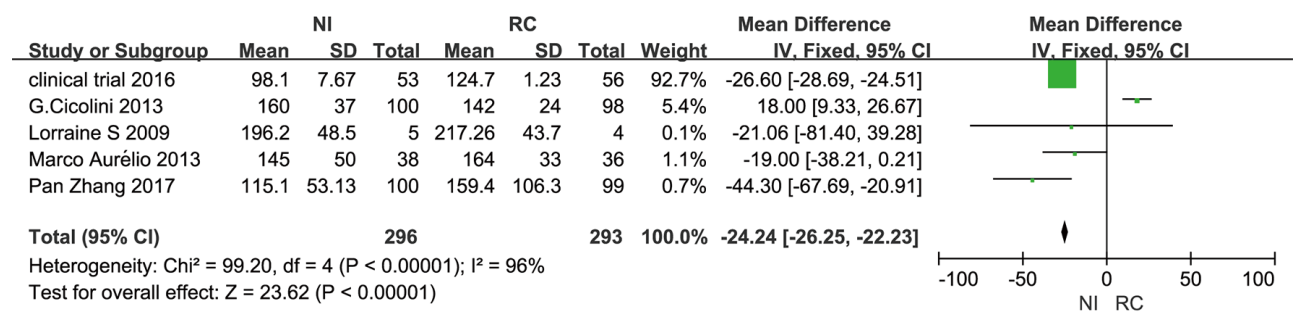

Figure 8 Forest map of triglyceride comparisons between the NI and RC groups. NI, nursing intervention; RC, nursing care.

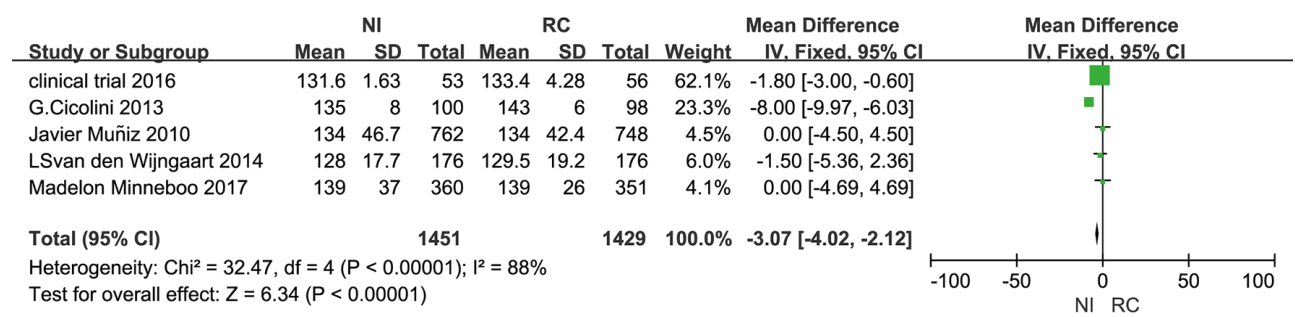

Figure 9 Sensitivity analysis forest map.

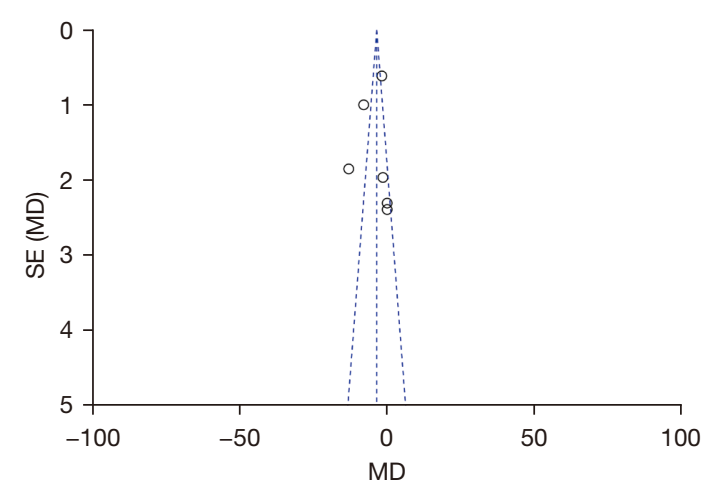

Figure 10 Begg's funnel plot of publication bias.

the number of relevant studies is limited by relatively small case numbers (33-35). In future trials and studies, we need to provide a more reliable theoretical and experimental basis for applying NI during the later stages of CVD treatment.

\section{Acknowledgments}

Funding: None.

\section{Footnote}

Reporting Checklist: The authors have completed the PRISMA reporting checklist. Available at https://dx.doi. org/10.21037/apm-21-2189

Conflicts of Interest: Both authors have completed the ICMJE uniform disclosure form (available at https://dx.doi. org/10.21037/apm-21-2189). The authors have no conflicts of interest to declare.

Ethical Statement: The authors are accountable for all aspects of the work in ensuring that questions related to the accuracy or integrity of any part of the work are appropriately investigated and resolved.

Open Access Statement: This is an Open Access article distributed in accordance with the Creative Commons Attribution-NonCommercial-NoDerivs 4.0 International License (CC BY-NC-ND 4.0), which permits the noncommercial replication and distribution of the article with the strict proviso that no changes or edits are made and the original work is properly cited (including links to both the formal publication through the relevant DOI and the license). See: https://creativecommons.org/licenses/by-nc-nd/4.0/.

\section{References}

1. Solvang MM, Norekvål TM, Tell GS, et al. Attempts to improve and confidence in improving health behaviour in 40-49 year olds with and without coronary heart disease: 
The Hordaland Health Study. Eur J Cardiovasc Nurs 2016;15:e60-9.

2. Grandi SM, Shimony A, Eisenberg MJ. Bupropion for smoking cessation in patients hospitalized with cardiovascular disease: a systematic review and metaanalysis of randomized controlled trials. Can J Cardiol 2013;29:1704-11.

3. Patil SJ, Ruppar T, Koopman RJ, et al. Effect of peer support interventions on cardiovascular disease risk factors in adults with diabetes: a systematic review and metaanalysis. BMC Public Health 2018;18:398.

4. Katsagoni CN, Georgoulis M, Papatheodoridis GV, et al. Effects of lifestyle interventions on clinical characteristics of patients with non-alcoholic fatty liver disease: A metaanalysis. Metabolism 2017;68:119-32.

5. Lee MK, Suh SR. Effects of Peer-Led Interventions for Patients With Cancer: A Meta-Analysis Oncol Nurs Forum 2018;45:217-36.

6. Suissa K, Larivière J, Eisenberg MJ, et al. Efficacy and Safety of Smoking Cessation Interventions in Patients With Cardiovascular Disease: A Network Meta-Analysis of Randomized Controlled Trials. Circ Cardiovasc Qual Outcomes 2017;10:e02458.

7. Huang XL, Pan JH, Chen D, et al. Efficacy of lifestyle interventions in patients with type 2 diabetes: A systematic review and meta-analysis. Eur J Intern Med 2016;27:37-47.

8. Fridlund B, Jnsson AC, Andersson EK, et al. Essentials of Nursing Care in Randomized Controlled Trials of NurseLed Interventions in Somatic Care: A Systematic Review. Open J Nurs 2014. DOI:10.4236/ojn.2014.43023.

9. Clarkson MJ, Bennett PN, Fraser SF, et al. Exercise interventions for improving objective physical function in patients with end-stage kidney disease on dialysis: a systematic review and meta-analysis. Am J Physiol Renal Physiol 2019;316:F856-72.

10. van den Wijngaart LS, Sieben A, van $\operatorname{der}$ Vlugt M, et al. A nurse-led multidisciplinary intervention to improve cardiovascular disease profile of patients. West J Nurs Res 2015;37:705-23.

11. Minneboo M, Lachman S, Snaterse M, et al. CommunityBased Lifestyle Intervention in Patients With Coronary Artery Disease: The RESPONSE-2 Trial. J Am Coll Cardiol 2017;70:318-27.

12. Vílchez Barboza V, Klijn TP, Salazar Molina A, et al. Effectiveness of personalized face-to-face and telephone nursing counseling interventions for cardiovascular risk factors: a controlled clinical trial. Rev Lat Am Enfermagem 2016;24:e2747.
13. Zhang P, Hu YD, Xing FM, et al. Effects of a nurseled transitional care program on clinical outcomes, health-related knowledge, physical and mental health status among Chinese patients with coronary artery disease: A randomized controlled trial. Int J Nurs Stud 2017;74:34-43.

14. Cicolini G, Simonetti V, Comparcini D, et al. Efficacy of a nurse-led email reminder program for cardiovascular prevention risk reduction in hypertensive patients: a randomized controlled trial. Int J Nurs Stud 2014;51:833-43.

15. Saffi MA, Polanczyk CA, Rabelo-Silva ER. Lifestyle interventions reduce cardiovascular risk in patients with coronary artery disease: a randomized clinical trial. Eur J Cardiovasc Nurs 2014;13:436-43.

16. Evangelista LS, Heber D, Li Z, et al. Reduced body weight and adiposity with a high-protein diet improves functional status, lipid profiles, glycemic control, and quality of life in patients with heart failure: a feasibility study. J Cardiovasc Nurs 2009;24:207-15.

17. Muñiz J, Gómez-Doblas JJ, Santiago-Pérez MI, et al. The effect of post-discharge educational intervention on patients in achieving objectives in modifiable risk factors six months after discharge following an episode of acute coronary syndrome, (CAM-2 Project): a randomized controlled trial. Health Qual Life Outcomes 2010;8:137.

18. Bonfioli E, Berti L, Goss C, et al. Health promotion lifestyle interventions for weight management in psychosis: a systematic review and meta-analysis of randomised controlled trials. BMC Psychiatry 2012;12:78.

19. Wagner KH, Schwingshackl L, Draxler A, et al. Impact of dietary and lifestyle interventions in elderly or people diagnosed with diabetes, metabolic disorders, cardiovascular disease, cancer and micronutrient deficiency on micronuclei frequency - a systematic review and meta-analysis. Mutation Research - Reviews in Mutation Research 2021. doi: 10.1016/j.mrrev.2021.108367.

20. Helton TJ, Bavry AA, Kumbhani DJ, et al. Incremental effect of clopidogrel on important outcomes in patients with cardiovascular disease: a meta-analysis of randomized trials. Am J Cardiovasc Drugs 2007;7:289-97.

21. Cao X, Wong EM, Chow Choi K, et al. Interventions for Cardiovascular Patients with Type D Personality: A Systematic Review. Worldviews Evid Based Nurs 2016;13:314-23.

22. Schellenberg ES, Dryden DM, Vandermeer B, et al. Lifestyle interventions for patients with and at risk for type 2 diabetes: a systematic review and meta-analysis. Ann 
Intern Med 2013;159:543-51.

23. de Waure C, Lauret GJ, Ricciardi W, et al. Lifestyle interventions in patients with coronary heart disease: a systematic review. Am J Prev Med 2013;45:207-16.

24. Lawrence M, Pringle J, Kerr S, et al. Multimodal secondary prevention behavioral interventions for TIA and stroke: a systematic review and meta-analysis. PLoS One 2015;10:e0120902.

25. Waure CD, Lauret G, Ricciardi W, et al. Multiple lifestyle interventions for secondary prevention of coronary heart disease: a meta-analysis. Eur J Public Health 2013;23:t123.

26. van Ballegooijen AJ, Reinders I, Visser M, et al. Parathyroid Hormone is Associated with Higher Risk of Cardiovascular Diseases: A Systematic Review and Metaanalysis. Conference: Scientific Sessions of the AmericanHeart-Association on Epidemiology, 2013.

27. Santschi V, Chiolero A, Paradis G, et al. Pharmacist interventions to improve cardiovascular disease risk factors in diabetes: a systematic review and metaanalysis of randomized controlled trials. Diabetes Care 2012;35:2706-17.

28. Hartlage G, Janik M, Anadiotis A, et al. Prognostic value of adenosine stress cardiovascular magnetic resonance and dobutamine stress echocardiography in patients with lowrisk chest pain. Int J Cardiovasc Imaging 2012;28:803-12.

29. Ski CF, Jelinek M, Jackson AC, et al. Psychosocial interventions for patients with coronary heart disease and depression: A systematic review and meta-analysis. Eur J Cardiovasc Nurs 2016;15:305-16.

30. Hendriks JM, Johansson P, Strömberg A, et al. Sleep disordered breathing - a hidden co-morbidity in patients with atrial fibrillation? Eur J Cardiovasc Nurs 2014;13:480-2.

31. Appuhamy J. Effects of diet and exercise interventions on diabetes risk factors in adults without diabetes: metaanalyses of controlled trials. Diabetology and Metabolic Syndrome 2014;6:1-15.

32. Liu H. The effectiveness of lifestyle interventions on outcomes of patients with atrial fibrillation: a systematic review and meta-analysis. Tine Haworth Cardiovascular Research Day; 2018.

33. Chase JA, Bogener JL, Ruppar TM, et al. The Effectiveness of Medication Adherence Interventions Among Patients With Coronary Artery Disease: A Metaanalysis. J Cardiovasc Nurs 2016;31:357-66.

34. Paradise MB, Naismith SL, Davenport TA, et al. The impact of gender on early ill-health retirement in people with heart disease and depression. Aust N Z J Psychiatry 2012;46:249-56.

35. Pilz S, Gaksch M, O'Hartaigh B, et al. The role of vitamin $\mathrm{D}$ deficiency in cardiovascular disease: where do we stand in 2013? Arch Toxicol 2013;87:2083-103.

(English Language Editor: D. Fitzgerald)
Cite this article as: Zhang N, Fa T. A systematic review and meta-analysis of lifestyle nursing interventions for patients with cardiovascular disease. Ann Palliat Med 2021;10(10):1042510433. doi: 10.21037/apm-21-2189 